\section{Prevention and control of proliferative vitreoretinopathy: primary retinal detachment surgery using silicone oil as a planned two-stage procedure in high-risk cases}

PAlexander, R Prasad, A Ang, AV Poulson, JD Scott and MP Snead

\begin{abstract}
Aims For rhegmatogenous retinal detachment, reattachment with a single procedure is associated with better visual outcomes. In the past, silicone oil has been used mostly as a last resort following failed primary surgery. This study evaluates a novel approach to patients at high risk of primary failure, using silicone tamponade as the primary stage of a planned two-stage procedure.
\end{abstract}

Methods We report a series of $\mathbf{1 4 0}$ eyes that underwent primary surgery for

rhegmatogenous retinal detachment. Patients at higher risk of surgical failure (eg giant retinal tear, inability to posture, poor view, uncertainty of location of primary break, primary proliferative vitreoretinopathy (PVR), multiple tears with rolled posterior edges, retinoschisis/detachment, staphyloma with macular hole) were managed by a planned staged procedure using primary silicone oil tamponade. This was followed by silicone removal at a later date.

Results Fifty-four eyes underwent scleral buckling alone, with primary success in 52/54 (96\%). Fifty-three eyes underwent vitrectomy and gas, achieving primary success in 50/53 (94\%). Thirty-three eyes were classified high risk and managed with primary silicone. Silicone was safely removed in $22 / 25$. In eight eyes, silicone was retained without attempt at removal. In total, primary retinal reattachment was achieved in 128 of 140 eyes (91.4\%).

Of these, $124(97 \%)$ did not require long-term tamponade. Only four eyes (2.9\%) developed PVR.

Discussion A planned two-stage approach to highrisk cases of retinal detachment using primary silicone oil tamponade followed by silicone removal can achieve a high primary reattachment rate with less than $3 \%$ incidence of PVR.

Eye (2008) 22, 815-818; doi:10.1038/sj.eye.6702719; published online 2 February 2007

Keywords: retinal detachment; vitrectomy; silicone oil; proliferative vitreoretinopathy

\section{Introduction}

In 1904 the International Congress of Ophthalmology deemed retinal detachment to be untreatable. ${ }^{1}$ Since the pioneering work of Gonin, who showed that successful retinal reattachment can be achieved in $66 \%$ of cases, ${ }^{2}$ there have been numerous advances in surgical technique including binocular indirect ophthalmoscopy, ${ }^{3}$ scleral buckling, ${ }^{4}$ pars plana vitrectomy, ${ }^{5}$ perfluorocarbons ${ }^{6}$, and intraocular tamponade with long acting gases ${ }^{7}$ or silicone oil. ${ }^{8}$ Most contemporary reports involving a large number of consecutive cases suggest that a success rate of greater than $90 \%$ is achievable, but $10-20 \%$ require more than one operation for retinal reattachment (Table 1).
Vitreoretinal Service, Addenbrooke's Hospital, Cambridge, UK

Correspondence: MP Snead, Vitreoretinal Service, Addenbrooke's Hospital, Hills Road, Cambridge CB2 2QQ, UK Tel: + 441223216701 ; Fax: + 441223217968 E-mail: mps34@

cam.ac.uk

Received: 11 October 2006 Accepted: 24 November 2006

Published online: 2 February 2007

No proprietary interests or research funding Data have been presented as a poster at EU Retina Meeting, May 2006 
Table 1 Primary success rates from various published series 1973 present

\begin{tabular}{|c|c|c|c|c|c|}
\hline Unit & Date & Number of cases & Technique & Primary success rate $(\%)$ & Source \\
\hline London & 1973 & 452 & Buckles only & 75 & Chignell et al ${ }^{24}$ \\
\hline Iowa & 1973 & 863 & Buckles only & 76 & Rachal and Burton ${ }^{25}$ \\
\hline San Francisco & 1979 & 1008 & Buckles only & 84 & Grizzard et $a l^{26}$ \\
\hline Orebro & 1981 & 590 & Buckles only & 65 & Tornquist and Tornquist ${ }^{27}$ \\
\hline Helsinki & 1981 & 352 & Buckles only & Unknown & Laatikainen $e t a l^{28}$ \\
\hline Oklahoma & 1984 & 662 & Buckles only & 91 & Wilkinson and Bradford ${ }^{29}$ \\
\hline Madras & 1989 & 601 & Buckles only & 86 & Sharma et $a l^{30}$ \\
\hline Moorfields & 1997 & 153 & All & 80 & Sullivan et $a l^{31}$ \\
\hline Cambridge & 1997 & 160 & All & 90 & Comer et $a l^{32}$ \\
\hline Cambridge & 2004 & 110 & Buckles only & 99 & Ung et $a l^{16}$ \\
\hline Berlin & 2006 & 512 & All & 71 & Heimann et $a l^{17}$ \\
\hline
\end{tabular}
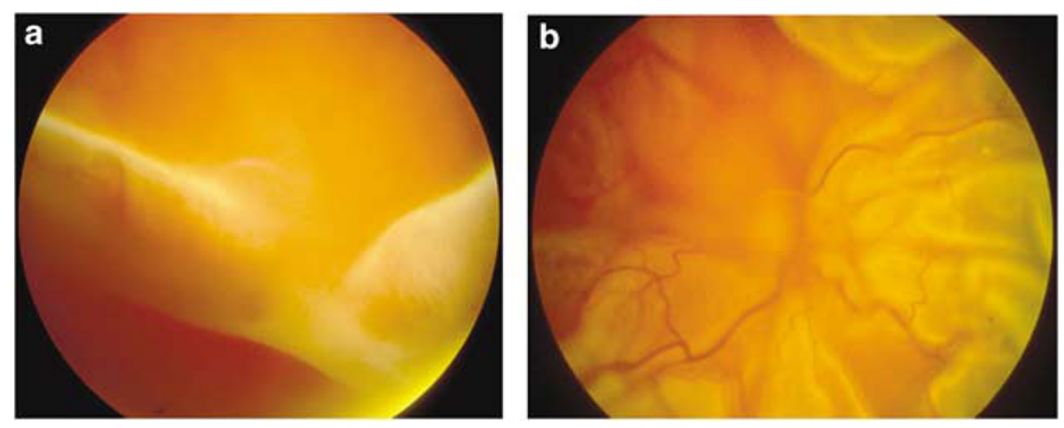

Figure 1 (a) and (b) A planned two-stage procedure is required to achieve primary reattachment in high-risk cases.

Proliferative vitreoretinopathy (PVR) is quoted as the commonest cause of final failure to reattach the retina. ${ }^{9}$ The pathogenesis of PVR is complex and many studies have investigated the risk factors for its development. ${ }^{10-13}$ We suggest, however, that one of the major principal causes of PVR is failed primary surgery. ${ }^{14}$ Retinal reattachment with a single procedure is associated with a better visual outcome and reduced morbidity, ${ }^{15}$ and success therefore in primary surgery is of immense importance. Despite this, primary reattachment rates have only been assessed by a few series involving large numbers of cases. Algorithms for the management of different subgroups and the refinement of case selection have led to reports of up to $99 \%$ success for primary scleral buckling surgery. ${ }^{16}$ The success of more complex cases that may require an internal approach have shown a similar but less dramatic improvement in this challenging subgroup of cases. Most series report a primary failure rate of $10-20 \%$ (Table 1) and the use of silicone has been reserved by some surgeons as a last resort procedure following failed primary surgery. Many of these may require permanent tamponade and may be associated with a poor visual prognosis.

This study reports the use of silicone in a similar group of cases, but significantly as the primary tamponade agent in cases of retinal detachments with a high risk of primary failure (Figure 1). The aim of such an approach for high-risk cases was to improve the chances of primary reattachment, and to thereby reduce or avoid the use of silicone oil as a secondary salvage tamponade, where the risks of safe removal are unpredictable.

\section{Methods}

All patients under the care of a single surgical team who underwent primary surgery for rhegmatogenous retinal detachment during a single year (January to December 2003) were included in the study. Pre-operative assessment included indirect ophthalmoscopy and slit-lamp biomicroscopy of the vitreous, posterior hyaloid membrane, and retina of both eyes. Patients with high-risk characteristics (Table 2) were managed with primary silicone oil tamponade single port. Pars planar vitrectomy was performed under indirect ophthalmoscopic control with direct silicone exchange; 5700 centistoke silicone oil was used in all cases.

Adjunctive scleral buckling was performed in cases with inferior retinal breaks or primary PVR at presentation. Retinal breaks were treated with monitored transscleral cryotherapy. Silicone oil was removed as a staged second procedure at least 3 months later. 
Table 2 High-risk categories

\begin{tabular}{|c|c|}
\hline Giant tear & $\begin{array}{l}\text { Multiple/rolled tears in }>2 \\
\text { quadrants }\end{array}$ \\
\hline $\begin{array}{l}\text { Anticipated inability to } \\
\text { posture }\end{array}$ & Retinoschisis detachment \\
\hline Poor or compromised view & Coloboma breaks \\
\hline $\begin{array}{l}\text { Uncertainty of primary } \\
\text { break }\end{array}$ & Large, ragged inferior breaks \\
\hline PVR $(>C 2)$ at presentation & $\begin{array}{l}\text { Staphyloma with macular } \\
\text { hole }\end{array}$ \\
\hline
\end{tabular}

Patients without any high-risk characteristics were managed with conventional scleral buckling or two-port vitrectomy under indirect control with gas tamponade. All surgical procedures were conducted under general anaesthetic. All patients had follow-up for at least 12 months.

The primary outcome measures were the retinal reattachment rate at 12 months following primary repair, and the incidence of proliferative vitreoretinopathy.

\section{Results}

A total of 140 eyes of 131 consecutive unselected patients underwent surgical repair for primary rhegmatogenous retinal detachment. Fifty-four eyes underwent primary repair with scleral buckling alone, with primary reattachment in 52 cases $(96.3 \%)$. Fifty-three eyes underwent vitrectomy with gas tamponade (with or without scleral buckling) and primary success was achieved in 50 cases $(94.3 \%)$.

Thirty-three eyes were classified as high risk and, therefore, had planned primary silicone oil tamponade. The second stage was carried out in 25 eyes and was safely achieved in 22 cases. The mean time between primary surgery and silicone removal was 7.9 months (range 3-18 months).

Silicone was not removed from eight eyes for a variety of ophthalmic and general medical reasons. Three eyes had primary macular hole detachment associated with high myopia, posterior staphyloma, and myopic chorioretinal atrophy with a poor prognosis for central vision. Although all were successfully re-attached with restoration of peripheral vision, silicone removal was not considered to offer any visual benefit to the patient. One eye had a total detachment and no further surgery was attempted. A further three eyes had persistent shallow inferior retinal detachments precluding silicone oil removal. In the remaining patient, primary retinal reattachment was successfully achieved, and removal of silicone oil was offered, but the patient declined. In this subgroup of eight cases, two had elevated intraocular pressure requiring continuing hypotensive treatment.
One of these patients also developed silicone oil emulsification. No patients developed keratopathy.

In total, primary retinal reattachment was achieved in 128 eyes of 140 (91.4\%). Of these, 124 cases (97\%) did not require long-term tamponade. Only four eyes (2.9\%) developed PVR.

\section{Discussion}

This study showed an overall success rate of $91 \%$ in an unselected consecutive series of patients undergoing primary surgery for rhegmatogenous retinal detachment including giant retinal tear, schisis, posterior breaks, and primary PVR. By adopting a planned two-stage approach to the management of cases judged to be at high risk of primary surgical failure, the incidence of PVR was reduced from greater than $10 \%{ }^{17}$ to less than $3 \%$.

Despite its proven effectiveness as an intraocular tamponade, ${ }^{18}$ silicone oil has often been considered a last resort following failure of primary retinal reattachment surgery. Its use in primary reattachment procedures has been restricted to cases of giant retinal tears, although good results with silicone oil for macular hole detachments in staphylomas of highly myopic eyes have also been reported. ${ }^{19,20}$ Our study demonstrates that by adopting a planned two-stage approach using silicone oil in other high-risk categories, an improved primary reattachment rate can be achieved compared to that reported in other series involving similar cases. Using this approach the option to remove the silicone can be exercised at a later stage and in a planned manner. Silicone oil was retained in eight patients, four of whom had complete retinal reattachment. In one case, silicone was retained because of patient choice. In three cases, removal of silicone was not indicated or attempted because of poor central visual prognosis. None of these patients developed keratopathy. Two had elevated intraocular pressures requiring long-term treatment and one of these patients also demonstrated silicone oil emulsification.

The Silicone Study Group used randomised prospective multicentre trials to compare silicone oil with gas tamponade in the treatment of rhegmatogenous retinal detachment with PVR. They were designed to test the hypothesis that the improved anatomical results of silicone might be offset by its complications. However, evidence from the Silicone Study Group has been useful in establishing that most of the complications described previously in association with silicone oil are caused by the pathological process of PVR rather than the silicone itself. ${ }^{21}$ Silicone Study Report 2 showed that intraocular tamponade (either silicone or C3F8) had no influence on the incidence of keratopathy. ${ }^{22}$ Keratopathy and blindness were more frequent in eyes randomised to 
receive SF6. ${ }^{18}$ Chronic intraocular pressure elevation was more prevalent in eyes randomised to silicone oil than C3F8, but was uncommon (8 vs $2 \%, P<0.05){ }^{23}$

In conclusion, we report the selected use of silicone as a planned two-stage approach to primary

rhegmatogenous retinal detachment repair in patients at high risk of primary surgical failure. Reattachment rates are higher than in previously reported series, rates of PVR are low, and the need for long-term silicone oil tamponade is minimised.

\section{References}

1 Duke-Elder S, Dobree JH. Detachment and folding of the retina. In: Duke-Elder S, (eds). System of Ophthalmology. Diseases of the Retina 10. St Louis: Mosby, 1967 pp 771.

2 Gonin J. Le décollement de la rétine. Lausanne: Payot et Cie, 1934.

3 Schepens CL. A new ophthalmoscope demonstration. Trans Am Acad Ophthalmol Otolaryngol 1947; 51: 298.

4 Custodis E. Die Behandlung der Netzhautablösung durch umschriebene Diathermiekoagulation und einer mittels Plombenaufnähung erzeugten Eindellung der Sklera im Bereich des Risses. Klin Monatsbl Augenheilkd 1956; 129: 476.

5 Machemer R, Norton EWD. A new concept for vitreous surgery: 3 indications and results. Am J Ophthalmol 1972; 74: 1034-1056.

6 Chang S. Low viscosity liquid fluorochemicals in vitreous surgery. Am J Ophthalmol 1987; 103: 38-43.

7 Norton EW. Intraocular gas in the management of selected retinal detachments. Trans Am Acad Ophthalmol Otolarungol 1973; 77: 85-98.

8 Cibis PA, Becker B, Okun E, Canaan S. The use of liquid silicone in retinal reattachment surgery. Arch Ophthalmol 1962; 68: 590-599.

9 Kon CH, Asaria RHY, Occleston NL, Khaw PT, Aylward GW. Risk factors for proliferative vitreoretinopathy after primary vitrectomy: a prospective study. $\mathrm{Br} J$ Ophthalmol 2000; 84: 506-511.

10 Yoshino $Y$, Ideta $H$, Nagasaki $H$, Uemura A. Comparative study of clinical factors predisposing to proliferative vitreoretinopathy. Retina 1989; 9: 97-100.

11 Girard P, Mimoun G, Karpouzas I, Montefiore G. Clinical risk factors for proliferative vitreoretinopathy after retinal detachment surgery. Retina 1994; 14: 417-424.

12 Cowley M, Conway BP, Campochiaro PA, Kaiser D, Gaskin $\mathrm{H}$. Clinical risk factors for proliferative vitreoretinopathy. Arch Ophthalmol 1989; 107: 1147-1151.

13 Bonnet M. Clinical risk factors for vitreoretinal proliferation in rhegmatogenous retinal detachment. J Fr Ophthalmol 1994; 17: 530-540.

14 Scott JD. Duke Elder Lecture: prevention and perspective in retinal detachment. Eye 1989; 3: 491-515.

15 Wilkinson CP, Rice TA. Michels Retinal Detachment, 2nd edn. St. Louis: Mosby, 1997.
16 Ung T, Comer MB, Ang AJ, Sheard R, Lee C, Poulson AV et al. Clinical features and surgical management of retinal detachment secondary to round retinal holes. Eye 2005; 19: 665-669.

17 Heimann H, Zou X, Jandeck C, Kellner U, Bechrakis N, Kreusel KM et al. Primary vitrectomy for rhegmatogenous retinal detachment: an analysis of 512 cases. Graefe's Arch Clin Exp Ophthalmol 2006; 244: 69-78.

18 The Silicone Study Group. Vitrectomy with silicone oil or sulfar hexafluoride gas in eyes with severe prolifeatigve vitreoretinopathy. Results of a randomised clinical trial. Silicone study report 1. Arch Ophthalmol 1992; 110: 770-779.

19 Chen YP, Chen TL, Yang KR, Lee WH, Kuo YH, Chao AN et al. Treatment of retinal detachment resulting from posterior staphyloma-associated macular hole in highly myopic eyes. Retina 2006; 26: 25-31.

20 Scholda C, Wirtitsch M, Biowski R, Stur M. Primary silicone oil tamponade without retinopexy in highly myopic eyes with central macular hole detachments. Retina 2005; 25: 141-146.

21 Snead MP. Ocular therapy with silicone oils. Curr Op Ophthal 1993; 4: 36-43.

22 The Silicone Study Group. Vitrectomy with silicone oil or perfluoropropane gas in eyes with severe proliferative vitreoretinopathy: results of a randomised clinical trial. Silicone study report 2. Arch Ophthalmol 1992; 110: 780-792.

23 Barr CC, Stern W, Lai MY, Jean JS, Linton KLP, Trese M et al. Postoperative intraocular pressure abnormalities in the silicone study: Silicone Study Report 4. Ophthalmology 1993; 100: 1629-1635.

24 Chignell AH, Fison LG, Davies EW, Hartley RE, Gundry MF. Failure in retinal detachment surgery. Br J Ophthalmol 1973; 57: 525-530.

25 Rachal WF, Burton TC. Changing concepts of failures after retinal detachment surgery. Arch Ophthalmol 1979; 97: 480-483.

26 Grizzard WS, Hilton GF, Hammer ME, Taren D. A multivariate analysis of anatomic success of retinal detachments treated with scleral buckling. Graefes Arch Clin Exp Ophthalmol 1994; 232: 1-7.

27 Tornquist R, Tornquist P. Retinal detachment: a study of a population-based patient material in Sweden 1971-1981 III. Surgical results. Acta Ophthalmol 1988; 66: 630-636.

28 Laatikainen L, Harju H, Tolppanen EM. Post operative outcome in rhegmatogenous retinal detachment. Acta Ophthalmol 1985; 63: 647-655.

29 Wilkinson CP, Bradford RH. Complications of draining subretinal fluid. Retina 1984; 4: 1-4.

30 Sharma T, Challa JK, Ravishankar KV, Murugesan R. Scleral buckling for retinal detachment: predictors for anatomic failure. Retina 1994; 14: 338-343.

31 Sullivan PM, Luff AJ, Aylward GW. Results of primary retinal reattachment surgery: a prospective audit. Eye 1997; 11: 869-871.

32 Comer MB, Newman DK, George ND, Martin KR, Tom BDM, Moore AT. Who should manage primary retinal detachments? Eye 2000; 14: 572-578. 